\title{
Triunfos de la Casa de Austria: ENTRADAS REALES EN LA CORTE DE MADRID
}

Juan Chiva Beltrán

Universitat Jaume I

Resumen: En el presente artículo se estudia el ceremonial de entrada regia en la corte de Madrid durante el siglo XVII, a través de un importante documento, la Etiqueta de 1651, conservado en el Archivo General del Palacio Real de Madrid. Se analizan por tanto las entradas triunfales en que un monarca hispano hacía su primer ingreso como tal en la corte, las ceremonias más relevantes en las mismas, la trama de calles y plazas por las que se desenvolvían, los principales protagonistas de las mismas y los edificios e instituciones que más relevancia obtuvieron durante estos años del Siglo de Oro, de la gran fiesta barroca.

Palabras clave: Entrada Triunfal, Madrid, Casa de Austria, Fiesta Barroca

ABSTRACT: In this paper we study the royal entry ceremonial into the Madrid court in the Seventeenth Century, through an important document, the Etiqueta de 1651, preserved in the Archivo General del Palacio Real of Madrid. We analyze the entries in which a Spanish monarch made his first entry in the court, the most important ceremonies, the network of streets and squares of the parades, its main protagonists and the buildings and institutions that were more relevant during this Golden Century, during this great Baroque Festivities.

Keywords: Triumphal Entry, Madrid, House of Austria, Baroque Festivities 
$\mathrm{L}$ as entradas reales son una de las ceremonias de la Edad Moderna que más relación guarda con el momento clave de la transmisión del poder, ya que se trata del ritual mediante el cual un nuevo monarca accede al trono de forma magnánima y frente al pueblo, su primera gran entrada triunfal como rey. Las entradas triunfales son un tipo de ceremonia donde un personaje de gran importancia ingresa en una ciudad, ${ }^{1}$ para lo que todo el aparato ceremonial y artístico de la misma se vuelca al servicio del lujo y el engalanamiento, alcanzando el arte efímero gran importancia y difusión y siendo su forma más exitosa el arco triunfal. ${ }^{2}$ Con estos aparatos efímeros se transmite a los asistentes y espectadores el cuerpo ideológico de la misma, expuesto claramente en el programa iconográfico que cubrirá buena parte de estos arcos, altares o enmascaramientos. Se trata de una ceremonia de raíz romana, el triumphus, ${ }^{3}$ mantenida en su esencia en los recibimientos a monarcas en la Edad Media pero que se recupera con enorme fuerza ya durante el Renacimiento, como un elemento cultural más en el momento cumbre de la recuperación del mundo antiguo. ${ }^{4}$ En este trabajo se va a analizar en profundidad la plasmación concreta de este ceremonial en la corte hispánica a mediados del siglo XVII, mediante la información aportada por una interesantísima etiqueta protocolaria conservada en el Archivo General del Palacio Real, Madrid.

\section{La Casa de Austria, la monarquía hispánica y las entradas triun- FALES}

Con la llegada del Renacimiento, la recuperación de las entradas triunfales se evidencia sobre todo en Italia y Flandes, incluso en las formas

1. Ver las múltiples relaciones entre poder, fiesta y arte en Mínguez, V., «Arte, espectáculo y poder en la fiesta novohispana», en PÉrez Martínez, H. (ED.), México en fiesta, El Colegio de Michoacán, Secretaría de Turismo, Zamora (México), 1998. pp. 315 - 329.

Una obra clave para estudiar diferentes estadios de la historia de la fiesta es Schultz, U., La fiesta. Una historia cultural desde la Antigüedad hasta nuestros días, Alianza Editorial, Madrid, 1993. En el mismo se llega a hablar de Egipto o Mesopotamia antiguos y sus festividades, pasando por las épocas de las que se habla en este trabajo hasta llegar a momentos tan recientes como el Festival de Woodstock.

2. El importante término «arte efímero» es acuñado por Yves Bottineau. Ver su importante artículo Bottineau, Y., «Architecture Ephémère et Baroque Espagnol», en Gazette des Beaux-Arts, LXXI, vol. I, pp. 213 y ss.

3. Para más información sobre estas ceremonias ver referencias bibliográficas tan interesantes como:

Ferrer Maestro J., «El triunfo, la ovatio y el botín. Escenografía romana del uso aprovechable de la guerra», en Heimann, H-D., Knippschild, S. y Mínguez, V., Ceremoniales, ritos y representación del poder, Col-lecció Humanitats, Publicacions Universitat Jaume I, Castelló, 2004.

BRINGmANN, K., «El triunfo del emperador y las Saturnales de los esclavos en Roma», en SCHUlTz, U., La fiesta. Una historia cultural desde la Antigüedad hasta nuestros días, Alianza Editorial, Madrid, 1993.

Versnel, H.S., Triumphus. An inquiry into the Origin, Developement and Meaning of the Roman Triumph, Leiden, 1970. Además, una serie de autores clásicos nos proporcionan interesantes fuentes acerca de estos triunfos romanos, son Plinio, Estrabón, Dionisio, Zonaras o Plutarco.

4. Strong, R: Arte y poder. Fiestas del Renacimiento. 1450-1650. Ed. Alianza Forma, Madrid, 1988. Es sin ninguna duda el gran clásico para el estudio de la fiesta durante el Renacimiento.

OlEzA, J.: «Las transformaciones del fasto medieval» en QUiTANTE, L. (ED.): Teatro y espectáculo en la Edad Media. Actas Festival d'Elx 1990, Ed. Instituto de Cultura «Juan Gil-Albert», Alicante, 1992. pp. 47-64. Se acerca a las celebraciones hispanas de entrada triunfal durante la Edad Media. 


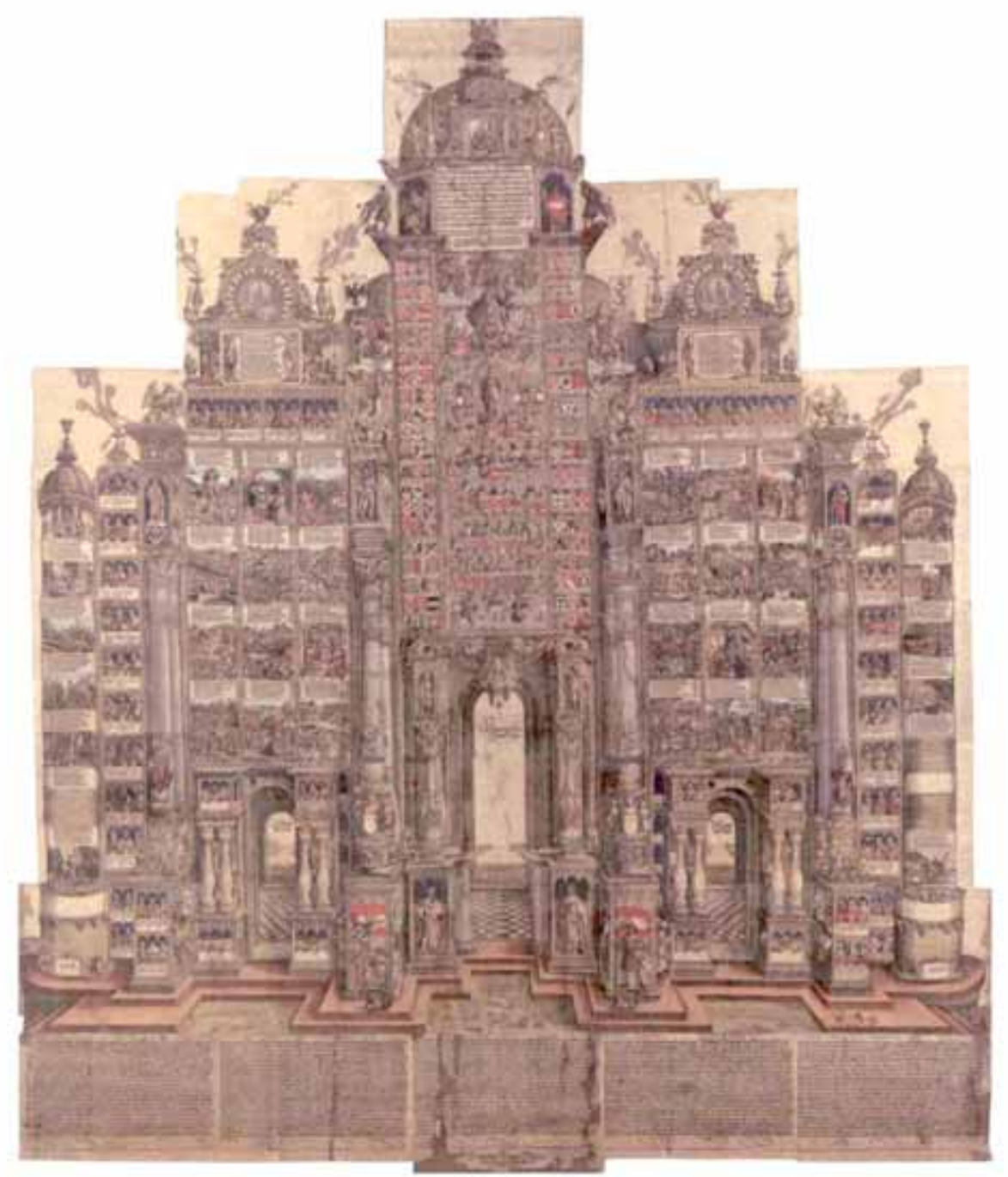

Fig. 1. Alberto Durero, Arco de Triunfo (1515). Entalladura, 274 x 190 mm. Biblioteca de la Albertina, Viena. Inv.DG 1931/973

arquitectónicas propias: los arcos de triunfo clásicos, utilizando para el programa iconográfico de las festividades la mitología y alegorías antiguas, así como la historia y elementos decorativos propios de la civilización grecorromana. Pese a que los arcos y estructuras italianas sean las primeras en acercarse de nuevo a la tradición clásica, ya hacia 1515 el artista germánico Alberto Durero está realizando sus magníficos bocetos para la iconografía triunfal imperial. De esta forma, durante la primera mitad del siglo XVI, el emperador romano-germánico Maximiliano I será protagonista de constantes 
triunfos que demuestren su gran poder y su hegemonía incluso por encima del poder papal. Para recordar estos triunfos, en la década de 1510 el emperador contará con grandes artistas alemanes para recrear sus carros y arcos triunfales, artistas de la talla de Alberto Durero o Albrecht Altdorfer, dos de los grandes humanistas alemanes. ${ }^{5}$

Por tanto la casa de Austria, en su rama alemana, está ya totalmente vinculada a inicios del siglo XVI a las nuevas formas ceremoniales surgidas en Italia que están expandiéndose por todo el continente, lo que confirma a los Habsburgo como una de las dinastías europeas de vocación más decididamente moderna, impulsando la difusión del Humanismo, el Renacimiento y sus expresiones culturales en todos sus dominios. Para el caso de la monarquía hispánica, tras el reinado de los Reyes Católicos y la sucesión en la persona de Juana de Castilla, la casa de Austria desembarcará en la península ibérica en la figura del también emperador Carlos $\mathrm{V}$, con el que llegarán a los reinos peninsulares unas nuevas costumbres y etiquetas ceremoniales, las propias de una dinastía moderna ya asumidas por su abuelo Maximiliano y que se difundirán rápidamente por estos nuevos y vastos dominios, que incluían buena parte del Mediterráneo y la recientemente descubierta América. La importancia del «nuevo cesar» Carlos V es inmensa a nivel político y cultural, y en la faceta que nos atañe será el personaje que, sin duda, marque la consolidación de esta nueva forma ceremonial, las entradas triunfales modernas, y de la adopción para estas de las formas renacentistas. Además Carlos V siempre tendrá muy claro el gran papel político que los viajes ceremoniales suponen para un monarca moderno, la gran fuerza que sobre los súbditos ejerce un lucimiento que recupera toda la gloria del mundo antiguo, convirtiéndose en una verdadera exaltación de la figura del soberano que cumple con creces su efectista intención de impresionar al pueblo. ${ }^{6}$ El siguiente monarca, Felipe II heredará la concepción de su padre en cuanto a las entradas triunfales y viajes ceremoniales como una razón de estado y gobierno, una importante herramienta para asentar el poder en sus vastos dominios, convirtiéndose de este modo en otro monarca eminentemente viajero. ${ }^{7}$

5. Tres magníficos grabados además de gran cantidad de bocetos evidencian este enorme interés de Maximiliano por las entradas triunfales y la iconografía que en ellas se podía transmitir al pueblo gobernado. Los tres grabados de mayor interés en este sentido se conservan en la colección de la Albertina de Viena (Austria): uno de Albrecth Altdorfer, Carro triunfal (1516), y otros dos de Alberto Durero, Arco Triunfal (1515) y Gran carro triunfal de Maximiliano (1518).

6. Este tema tiene una amplia bibliografía, desde el capítulo «Imágenes del Imperio. Carlos V y el viaje imperial», en el citado libro de R. STRONG (1988) a las monografías, entre las cuales cabe destacar el catálogo La fiesta en la Europa de Carlos V.

7. Francisco Javier Pizarro Gómez, Arte y espectáculo en los viajes de Felipe II, Ediciones Encuentro, Madrid, 1999.

Una fuente esencial para el estudio de los viajes felipinos es CALvete DE Estrella, El felicissimo viaie d'el muy Alto y muy Poderoso Principe don Phelippe, Hijo del Emperador don Carlos Quinto Máximo, desde su España a sus tierras de la baja Alemania, con la descripción de todos los Estados, de Brabante y Flandes... Año de MDLII. 


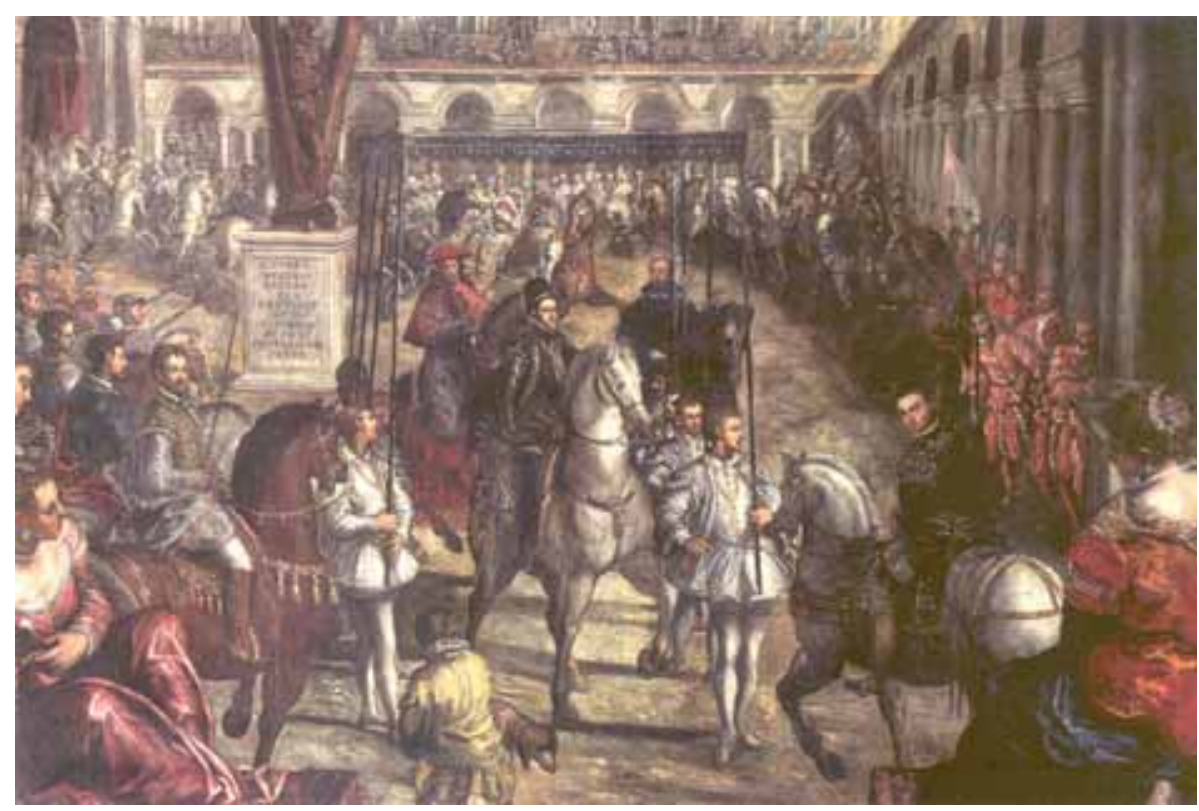

Fig. 2. Tintoretto (atribuido), Entrada de Felipe II en Mantua (Siglo Xvi). Óleo sobre lienzo. Alte Pinakothek, Munich

De esta forma, el Renacimiento como marco temporal y Flandes e Italia como marco espacial son el lugar y el momento en que se crea el modelo moderno de entrada triunfal, aunando las tradiciones del triumphus romano y el recibimiento medieval, tomando el ceremonial del segundo y cubriéndose de todo el esplendor, formalidades arquitectónicas e iconografía del mundo clásico. Con la expansión de la cultura renacentista por todo el continente europeo bajo el período imperial de Carlos V lo hace también esta tradición, que en cada zona se fusionará con las locales o regionales, consolidándose además el arco triunfal como punto clave de todo el ceremonial, gran aparato efímero artístico y soporte para desarrollar el programa iconográfico que mostrará la ideología que en cada fiesta se quiere divulgar.

\section{Los Austrias Menores y el Ciclo Barroco}

La tipología de entrada triunfal moderna va a seguir adelante con gran fuerza en el ciclo barroco, como muestran los ingresos de los reyes absolutos como Luis XIV de Francia y el interés de autores como Peter Paul Rubens, que incluso pinta una obra llamada Un triunfo romano ${ }^{8}$ en la que pretende plasmar esta antigua ceremonia, y crea bocetos para arcos de la entrada triunfal

8. Peter Paul Rubens, Un triunfo romano, siglo xviI, National Gallery, Londres. 


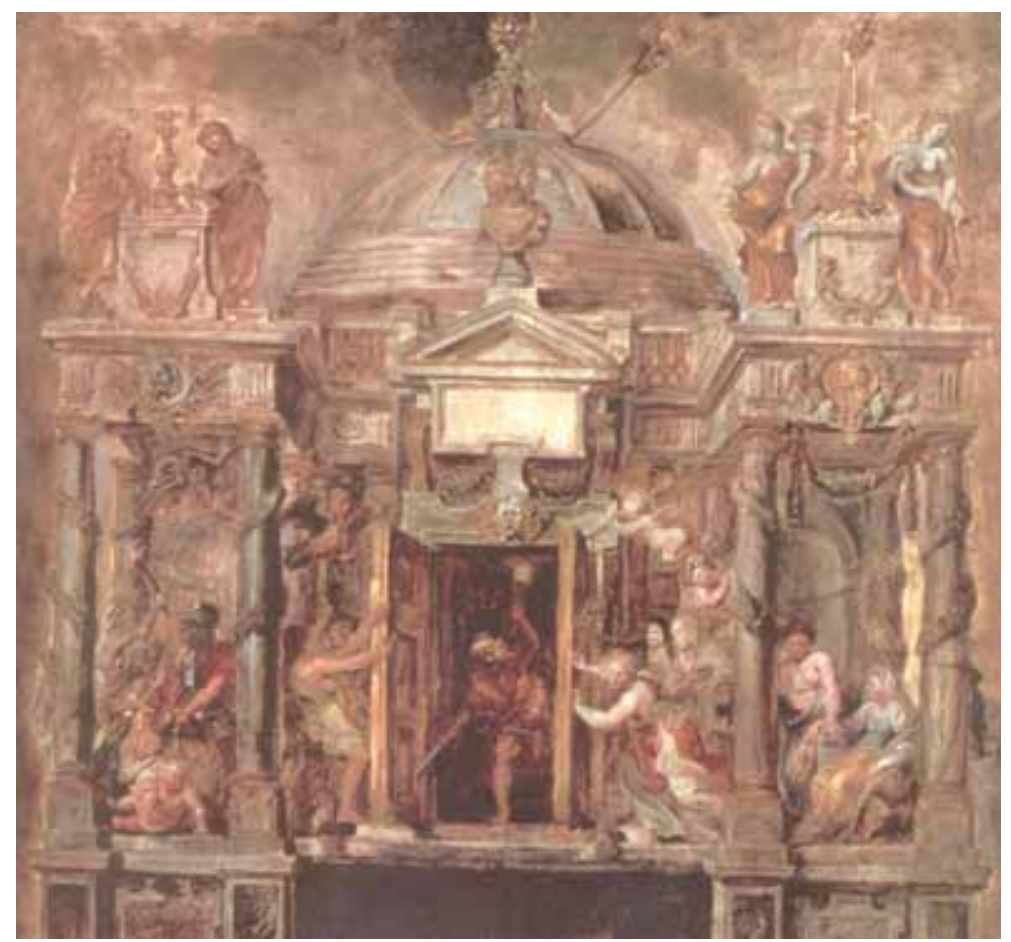

Fig. 3. Peter Paul Rubens, Templo de Jano (1635). Boceto para la entrada del cardenal infante Fernando en Amberes. Ermitage, San Petersburgo

en Amberes del cardenal infante Fernando de Austria. Los reyes se legitiman utilizando un discurso por el cual el poder se les concede por derecho divino, y por tanto son insustituibles. La fiesta se verá afectada por esta concepción, y será cada vez más efectista, más sorprendente y apoteósica. La fiesta barroca se ha definido como la más espectacular de todos los tiempos, las monarquías absolutas harán de ella un uso totalmente político, y las masas, muchas veces arruinadas y en estados de profunda crisis, tendrán a menudo demostraciones del poder de sus soberanos en estas fiestas.

Formalmente las entradas triunfales seguirán la tradición establecida durante el Renacimiento y tendrán un mismo esquema al menos hasta el siglo xIx. Solo se podrá hablar de cambios estilísticos en el arte efímero: los arcos de esta época dejaran las formas puramente clásicas para adentrarse en el mundo de claroscuros y efectismos barrocos, ya que las entradas han pasado a ser un elemento más de la cultura y evolucionarán al compás de la misma, se adaptarán perfectamente el estilo artístico imperante, ahora barroco, aunque posteriormente volverá el clasicismo con la «Era de las Luces».

Quizá el cambio más relevante de esta época lo encontramos en la concepción de la esencia de una entrada triunfal, que cambia muy al compás de las ideas políticas de la época. La noción que se extenderá por toda Europa es que la 


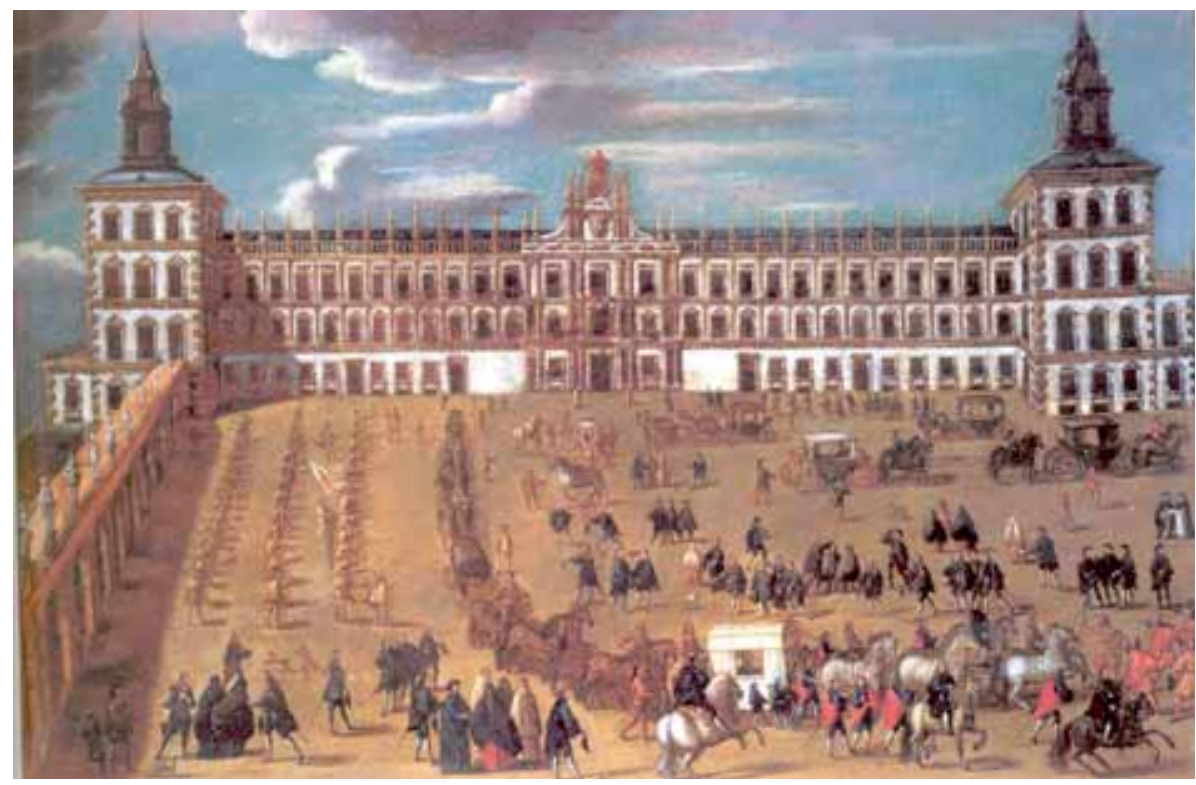

Fig. 4. Anónimo, Salida de Carlos II y don Juan José de Austria en carroza (siglo XviI). Óleo sobre lienzo. Colección Abelló, Madrid

entrada es realmente un triunfo, y el soberano un héroe, pero poco a poco, ante el aumento imparable del poder monárquico, las entradas se convertirán en meros procesos de afirmación del poder absoluto, en muestras de la lealtad de un pueblo a una dinastía. Otra consecuencia de esta nueva centralidad es que la fiesta se celebra básicamente en la corte, en los palacios reales y sus jardines. Cada monarquía nacional establecerá sus propias tradiciones para la entrada de los monarcas en la ciudad cortesana: las calles por donde se pasará, donde se colocarán los arcos, donde se ubicará en la procesión cada estamento, etcétera. ${ }^{9}$

También en la corte hispánica se va a trazar la confección de un ceremonial propio para la entrada de los reyes españoles en la corte, es decir, en la ciudad de Madrid. La diferencia esencial es que en este caso el protocolo a estudiar no es solo un día grande en una ciudad visitada, sino el momento de transición, un encumbramiento en el trono y un momento clave por tanto en la historia de la casa de Austria y de la monarquía hispánica. Al mismo tiempo esta entra en un periodo de colapso progresivo durante el gobierno de los llamados «Austrias Menores»: Felipe III (1598-1621), Felipe IV (1621-1665) y Carlos II (1665-1700). Esta etapa de crisis es, por el contrario, la época más floreciente de las artes españolas, el llamado Siglo de Oro, y la fiesta no escapará a ello. Las

9. El libro de varios autores Europa Triumphans. Court and civic festivals in early modern Europe, Londres, 1997, Ashgate, habla de diferentes tipos de ceremoniales barrocos, sobre todo entradas triunfales, en diferentes lugares de Europa, como Francia, Polonia, Alemania, Inglaterra e incluso Escandinavia. 
fiestas serán cada vez más esplendorosas, intentando reforzar la legitimidad monárquica y actuando como válvula de escape ante más que probables tensiones sociales. En esta época absolutista las celebraciones se centralizarán en la corte, ${ }^{10}$ y por tanto será Madrid el lugar donde las entradas sean más espectaculares, con un ceremonial que con las décadas quedará fuertemente establecido para la posterioridad.

\section{LA ETIQUETA PARA LA ENTRADA CON PALIO DE LOS SEÑORES REYES DESPUÉS DE SU EXALTACIÓN AL TRONO (1651): EL PROTOCOLO DE ENTRADA REAL}

Para el estudio del ceremonial de entrada triunfal en la corte hispana, existe una fuente realmente importante en el Archivo General del Palacio Real madrileño, que marca todo el protocolo para realizar una entrada en Madrid por parte de un rey en la jornada de su toma de posesión. Se trata de un documento fechado en 1651, justo en la mitad de la centuria y bajo el reinado de Felipe IV, el Rey Planeta. Así pues, cabe deducir que esta etiqueta sería un fiel reflejo de lo que se vive durante todo el siglo xviI, de cómo los Austrias, rodeados del fasto y opulencia propios del siglo, entraban en su capital. El texto aporta datos interesantes desde el primer momento, ya que lo primero que hace es definir el asunto que va a tratar, o sea una entrada triunfal en la corte, y lo hace de la siguiente manera:

Entrada pública se llama la que hacen los señores reyes después de su exaltación al trono y se entiende también por Coronación. ${ }^{11}$

Además la diferencia de lo que llama «salida pública» que sería la también etiquetada visita real a la Virgen de Atocha para dar gracias por algún hecho beneficioso para la familia, tales como bodas, nacimientos o recuperaciones tras una grave enfermedad. Esta aclaración pone antecedentes sobre la etiqueta que se va a desarrollar a continuación: se trata quizá de la entrada más importante que hace el rey en la corte, la primera de su reinado y en la que deberá demostrar que tras el momento de crisis que supone la muerte de su antecesor la dinastía se repone y seguirá propiciando momentos de gloria al pueblo. Es un momento clave de la continuidad dinástica, como también las exequias del monarca anterior. Se seguirá un marcado ritual desde la muerte y entierro del rey que empieza días antes de la entrada del sucesor, que tiene

10. Es algo que sucederá en todos los países europeos, el traslado de las grandes fiestas reales exclusivamente al ámbito cortesano. El cenit de estas fiestas barrocas se ha puesto muchas veces en las fiestas francesas en honor de Luis XIV celebradas en los palacios cercanos a París, destacando el gran Versalles, cuyos jardines daban mucho juego para todo tipo de festejos y celebraciones.

11. Archivo General de Palacio, Sección Histórica, Fondo Entradas Públicas, Caja 48, Expediente 2. Es el documento titulado: Etiqueta para la entrada con palio de los Señores Reyes después de su exaltación al trono. 

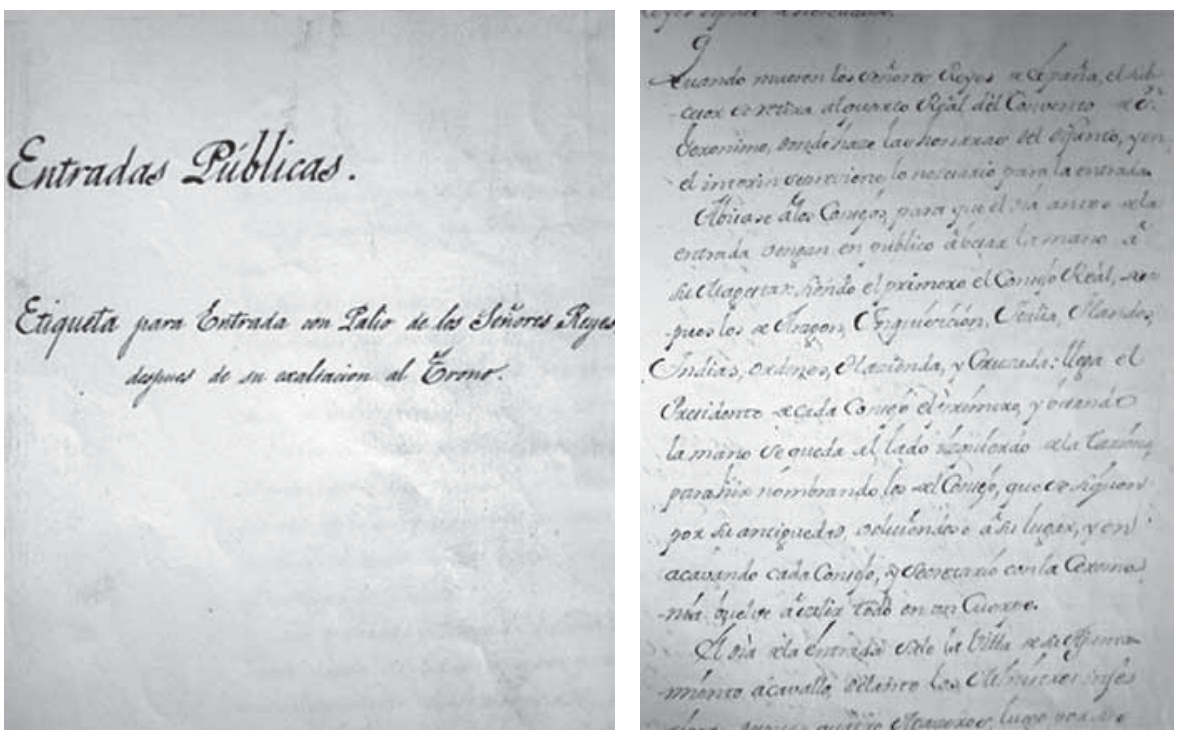

Fig. 5. Portada y primera Página, Etiqueta para la entrada con palio de los Señores Reyes después de su exaltación al trono (1651). Archivo General de Palacio, Sección Histórica, Fondo Entradas Públicas, Caja 48, Expediente 2

que ser tan grandiosa y espectacular como a mediados del siglo XVII el pueblo estaba acostumbrado a vivir. El estudio de esta ceremonia se hará centrado en la gran procesión como elemento de más importancia de la misma, estudiando en primer lugar la compleja composición de esta y en segundo lugar el itinerario o carrera.

Esta compleja ceremonia empezaba con la muerte y entierro del rey, con sus exequias, otra de las grandes ceremonias que marcan la transición del poder en el Antiguo Régimen, y el catafalco como gran expresión artística. ${ }^{12} \mathrm{El}$ sucesor se trasladaba entonces al Cuarto Real del Convento de San Jerónimo, a una celda preparada al efecto, donde debía pasar largas horas reflexionando, honrando a su difunto antecesor y preparando su entrada en la capital para que nada se saliese de lo establecido y todo el programa iconográfico y simbólico enviase a sus súbditos los mensajes oportunos y la tranquilidad necesaria en un momento de transición y por tanto de debilidad dinástica. Se tenía que dar imagen de riqueza y poder, de control de la situación y armonía política. En el mismo convento, el día antes de la entrada pública, se realizaba el besamanos por parte de los Consejos, a los que se abría excepcionalmente las puertas. El orden en la recepción de los Consejos era el siguiente: empezaba el Consejo Real, seguido por el de Aragón y el de la Inquisición, a continuación iban los de los territorios extrapeninsulares -Italia, Flandes e Indias-, seguidos por el de Órdenes, Hacienda y por último el de Cruzada. Este orden no es baladí,

12. JaVier VAREla: La muerte del rey. El ceremonial funerario de la monarquía española (1500-1885). , Ed. Turner, Madrid, 1990. 
puesto que la importancia del consejo, y en algún caso de sus integrantes, marcará posibles alteraciones, haciendo intuir las líneas maestras del gobierno del nuevo monarca. Cada Consejo entraría por separado de los demás en la habitación destinada por el Convento para esta recepción, entrando en primer lugar el presidente del Consejo, que besará la mano del monarca y hará genuflexiones de honor, para posteriormente dirigirse a la tarima, a la izquierda del rey, y desde allí ir llamando uno por uno a los miembros del consejo en cuestión por orden de antigüedad, que realizarán los mismos gestos que este. Posteriormente se retirará todo el Consejo en bloque, y se recibirá al siguiente. Es una ceremonia de gran importancia, ya que estas personas, a parte de las depuraciones y cambios que el nuevo monarca pueda hacer en los equipos de gobierno, son las que regirán la política de la monarquía y por tanto han de rendir honores al que va a ser su nuevo señor. Es un acto de fidelidad a la dinastía, de mucha significación en momentos en que se tiene que renovar cada uno de los lazos que mantenían el poder del anterior rey.

El mismo día de la entrada, el rey se trasladará al Palacio del Buen Retiro, ${ }^{13}$ lugar desde donde salen normalmente, ya sea porque el rey habitaba allí anteriormente o porque se traslada expresamente para ello. Antes de dar inicio al desfile recibirá a los representantes de la villa, también de especial relevancia ya que son las ciudades las que costean una entrada real. Estos saldrán de la Casa de la Villa a caballo, en orden ascendente de importancia de sus cargos, vestidos de luto y en dirección al besamanos real. De la misma manera que el día anterior, entrarán el regidor más antiguo y el corregidor a iniciar el besamanos, y colocados en una tarima llamarán por orden de antigüedad al resto. Luego salen en bloque y se dirigen a la carrera de San Jerónimo dónde en las esquinas con el paseo del Prado tienen preparada una grada alfombrada, con bancos, respaldo y barandilla. Esto denota la importancia de los gobiernos de las ciudades en esta etapa, y más aún el de la corte, ya que era el lugar donde normalmente habitaba el rey y tenía que costear muchas fiestas para la monarquía.

Otra ceremonia previa a la entrada es el acompañamiento del caballo hasta las graderías donde bajará el rey. Su estudio es realmente interesante y clarificador, pues nos da imagen de lo encorsetada que estaba toda la ceremonia y de cómo hasta el más mínimo detalle estaba etiquetado para que todo fuese como era preceptivo. El caballo será el mejor de que se disponga en ese momento y saldrá de las caballerizas reales, pero lo más interesante es ver cómo iba acompañado este animal hasta la gradería. La enumeración de las personas que preceden al caballo es exhausta: los oficiales menores de la Casa de los Pajes, diferentes mozos, los oficiales mayores de la anteriormente nombrada casa de tres en tres, los correos reales, el librador, diferentes ayudas de corte, los oficiales de las caballerizas, ballesteros, el armero mayor,

13. Aunque en las entradas más tempranas lo habitual fuese que empezase directamente el desfile desde el Cuarto Real del Convento de San Jerónimo. 


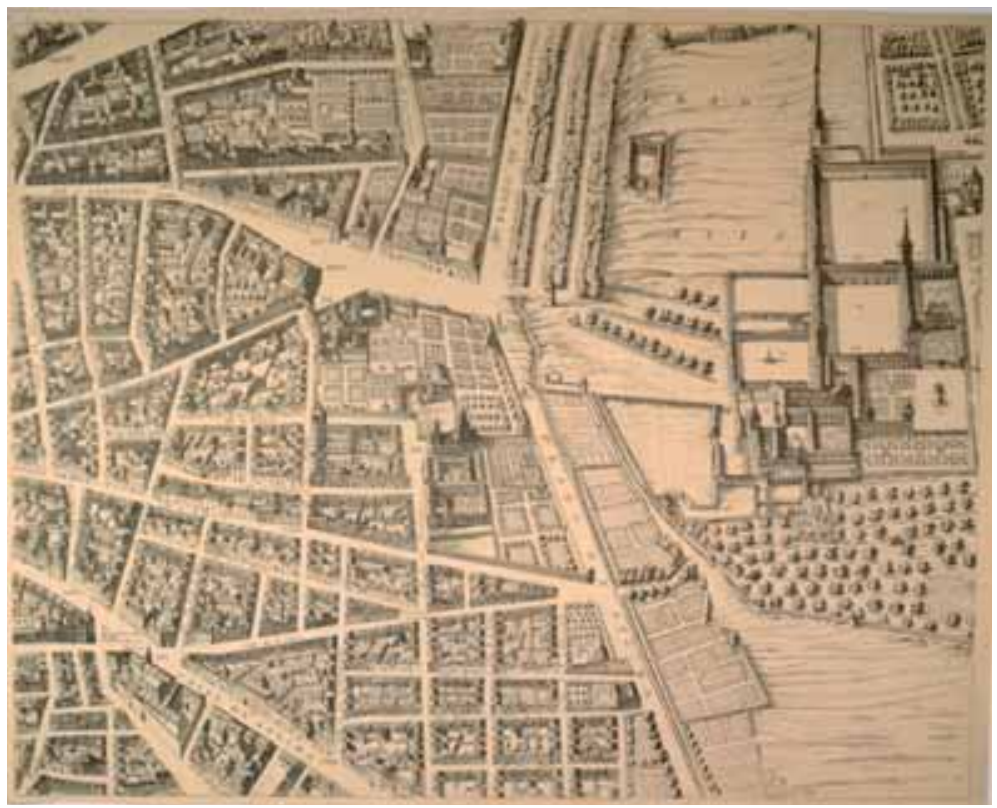

Fig. 6. Pedro Teixera Albernaz, Plano de Teixiera (1665). Amberes. Detalle de la zona del Palacio del Buen Retiro y Paseo del Prado, lugar de inicio de las entradas triunfales madrileñas

palafreneros, el sobrestante de coches, picadores, los pajes, los caballerizos más antiguos y el primer caballerizo. Al lado del caballo, el lacayo más antiguo lleva las riendas y un ayuda actuará de guardarnés, llevando la vara y el ferliz. ${ }^{14}$ Tras el caballo resta el caballerizo mayor y los caballos y coches de respeto, que por su multitud y belleza darán al desfile grandiosidad y majestuosidad. Una vez se llega donde esté el rey, en las gradillas colocadas en el zaguán para el efecto, se colocarán los guardias reales formando dos hileras: la de la derecha con la guardia española y la de la izquierda con la alemana. El lacayo más antiguo llevará el caballo hasta los pies de la gradilla, el primer caballerizo quitará el ferliz y la almántiga al caballo y las entregará al guardarnés. En el momento en que el monarca baje por la escalera principal y llegue frente al caballo, el caballerizo mayor le colocará el estribo del pie izquierdo y lo ayudará a subir. El primer caballerizo entregará el estribo del pie derecho al gentilhombre de cámara más antiguo, que será el encargado de colocárselo al rey, que ya estaba montado y preparado para salir por las calles madrileñas a realizar su primera entrada como rey, y a recibir las aclamaciones del pueblo.

14. El ferliz es una decoración de los caballos, que se quitará una vez el caballo haya de ser montado por su majestad, al igual que la almántiga, que se nombra más tarde. Ambos elementos eran llevados por un ayuda que actuaba como guardarnés, es decir la persona que lleva las ornamentaciones mientras el monarca va montado. 


\section{LA COMPOSICIÓN DEL DESFILE TRIUNFAL}

A continuación se debe explicar el orden del desfile triunfal que atravesará unas ornamentadas calles madrileñas, llenas de decoraciones efímeras y arcos triunfales. Es una composición muy compleja que muestra toda la clase alta de la corte del Antiguo Régimen, ordenada y desfilando frente a un público que queda boquiabierto ante sus autoridades vestidas lujosamente y con sus mejores caballos.

Al frente de toda la comitiva vuelven a situarse las guardias española y alemana, que despejarán el paso en las atiborradas calles de la capital, a los que sigue un cuerpo de trompeteros, costumbre que se hereda de la Roma republicana y se mantiene con los siglos. Seguidamente llegan las primeras autoridades del desfile a caballo: son los alcaldes de corte, capitanes ordinarios, caballeros, los títulos, los gentileshombres de cámara y los secretarios de estado, seguidos todos ellos de un cuerpo de maceros, portando sus mazas. A los lados de estos y formando hileras van los mayordomos de la corte y justo en este punto los Grandes de España participantes en el desfile. La etiqueta nos habla de la importancia del conde de Oropesa en esta ceremonia, ya que será el encargado de llevar en su hombro desnudo el real estoque, que le ha sido entregado por el soberano en la antecámara de los aposentos reales, siendo este un privilegio «preminencia de su cassa», ${ }^{15}$ otra muestra de la enorme importancia simbólica que guardan las posiciones y privilegios a distintas casas nobles en estos desfiles triunfales. Sigue la parte de comitiva con los caballerizos y a continuación ya desfila el rey, que va bajo palio llevado por importantes nobles y gentileshombres de la corte, y en un caballo ornamentado de las maneras más bellas posibles. Bajo palio sólo le acompaña el primer caballerizo a pie.

Detrás, y fuera del palio, encontramos el guardarnés, a quien siguen los embajadores ordenados por su procedencia, detalle que debió ser una verdadera manera de explicar cómo iban a seguir las alianzas y la diplomacia durante el nuevo reinado, cuáles iban a ser los estados que más importancia tendrían en la nueva política exterior. Seguidamente desfila el caballerizo mayor -si no lleva el estoque ya que es el primer sustituto del conde de Oropesa si este no puede presentarse el día de la entrada triunfal-, el mayordomo mayor, el capitán de la guardia de arqueros, los Consejos de Estado al completo, una compañía de arqueros a caballo, con pistolas y jabalinas y el resto de caballos de respeto del monarca. Cerrarán el coche del rey, los de respeto y los demás coches de la caballeriza real.

Hay que imaginar que todo este acompañamiento haría del desfile una gran procesión que recorrería las calles de Madrid durante horas, ante la atenta mirada de toda una ciudad que rendía pleitesía al rey y a todos los grandes personajes que envolvían a su persona, ya que avanzado el siglo XVII

15. AGP, Sección Histórica, Fondo Entradas Públicas, Caja 48, Exp. 2. 


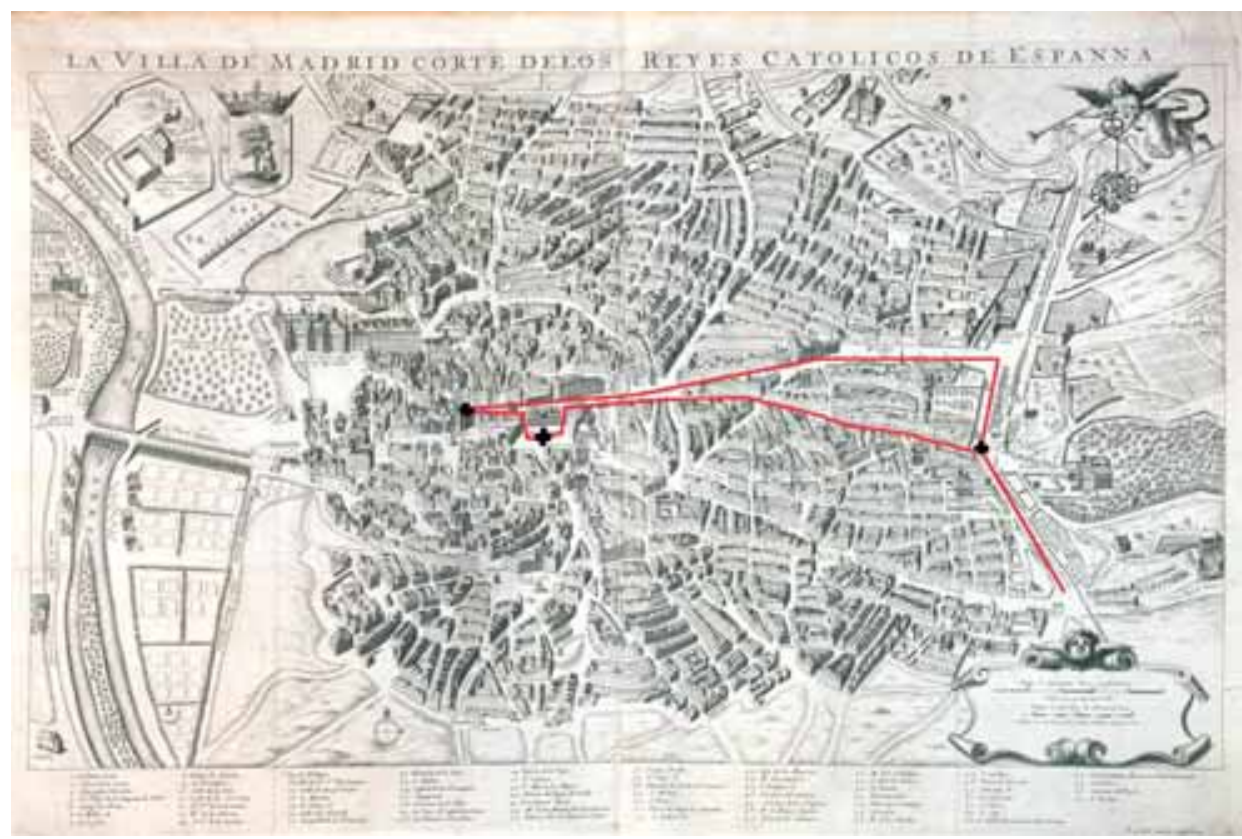

Fig. 7. F. De Witt, La Villa de Madrid Corte de los Reyes Católicos de Espanna (1657). Amsterdam. Gran mapa del Madrid del siglo XVII, con la ruta seguida por las entradas tirunfales trazada en rojo

la participación popular en las entradas triunfales es algo del pasado, estas sólo son un lucimiento del todopoderoso monarca absoluto español que se reviste de toda la pompa y lujo posibles, ante la atenazante crisis que el estado está sufriendo. Con esta procesión todo el organigrama del poder se ponía delante de la población y mostraba el engaño de un Estado fuerte, rico, estable y políticamente armonioso, cuando la realidad interior y exterior era muy diferente.

\section{LA CARRERA TRIUNFAL POR LAS CALLES DE MADRID}

En cuanto a la carrera, núcleo de calles por las cuales pasará este desfile, los puntos de partida de esta época pueden ser dos: en primer lugar el Cuarto Real del monasterio de San Jerónimo, en el Prado, habitado en numerosas ocasiones por Felipe IV, rey bajo el mandato del cual se estableció esta etiqueta, y el Palacio del Buen Retiro, cuya construcción se inició en 1629, ya en el reinado de Felipe IV, y que constó de más de 20 edificios, con jardines, estanques, fuentes y rodeado de una enorme suntuosidad. El arquitecto de tan magna obra fue Alonso Carbonell y se encontraba en el actual paseo del Prado. A partir de la invasión francesa de 1808 empezó un largo deterioro 


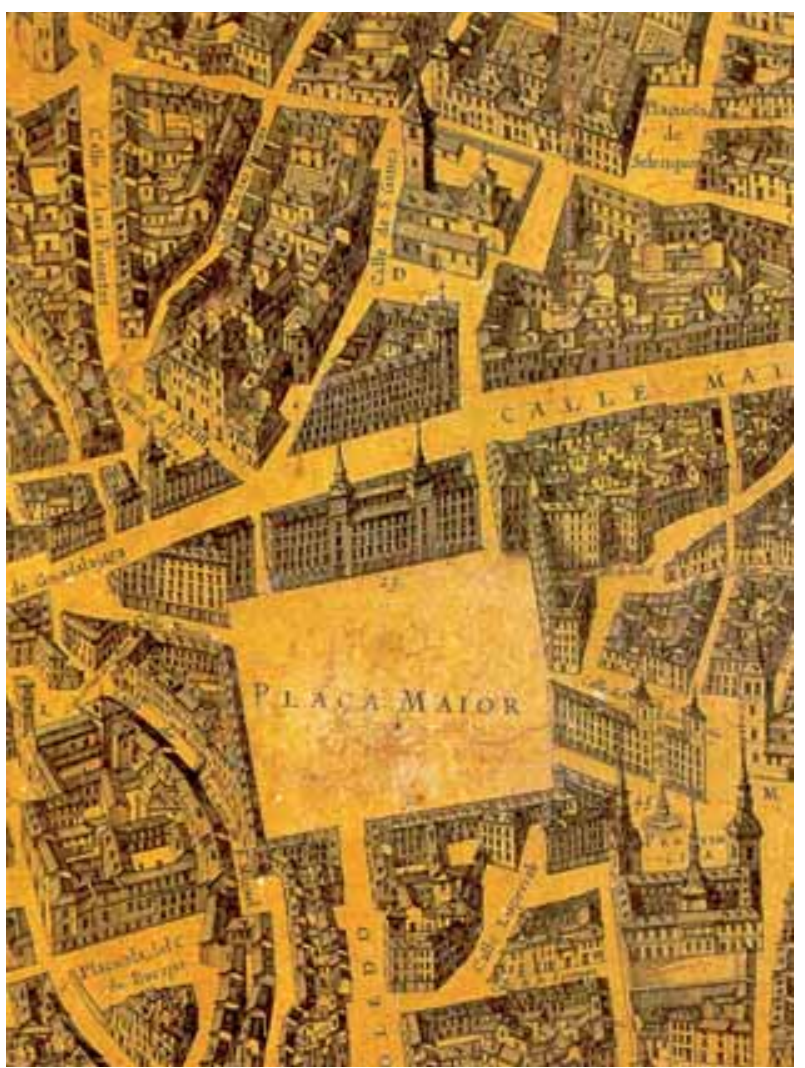

Fig. 8. Pedro Teixera Albernaz, Plano de Teixiera (1665). Amberes. Detalle de la Plaza Mayor y las calles aledañas

hasta que en el reinado de Isabel II se mandó su derribo, a excepción del Salón de Reinos, hoy Museo del Ejército, y del Salón de Baile, actual Casón del Buen Retiro. El rey aguardaría a la llegada de la comitiva con el caballo, y una vez éstos estuviesen preparados, bajaba por la escalera principal hasta unas gradillas colocadas para esta celebración en el zaguán de entrada. Se seguía el rígido ritual para la subida del monarca al caballo y una vez el animal montado salía el desfile triunfal, verdadero elemento central de las entradas públicas madrileñas de los soberanos hispánicos.

A partir de la construcción del Palacio del Buen Retiro las entradas saldrán desde allí mismo, pero si se iniciaran del convento de San Jerónimo la ruta seguida sería muy similar dada su cercanía. El cortejo ascendía por el paseo del Prado, con una importante primera parada en la esquina de esta avenida con la carrera de San Jerónimo, ya que allí se encontraban los representantes de la villa en una tarima sentados y también el palio que los nobles habían de llevar sobre la real persona hasta el final de la entrada triunfal. 
Se seguía por el Prado hasta la calle de Alcalá, que llevaría la entrada hasta el segundo punto neurálgico de la carrera: la iglesia de Santa María la Mayor, pasando por delante de la Puerta del Sol y por la calle Mayor hasta Santa María. Este templo, que en la actualidad no existe, estaba situado en la actual intersección de las calles Mayor y Bailén, era el más antiguo de Madrid y el más arraigado en la tradición popular, en parte por ser venerada en él la imagen de la Virgen de la Almudena, la devoción más querida tanto en la capital como en Toledo y la zona central de la Meseta. Su antigüedad es incierta, pero fue Alfonso VI quién la purificó bajo el rito romano para habilitarla al culto cristiano, teniendo desde entonces la prerrogativa de ser la iglesia Mayor de la villa de Madrid. Era un edificio pequeño, con una sólida torre cuadrada con ocho ventanales y el típico chapitel madrileño añadido en el siglo XVII. En 1782 fue de nuevo reformada por el arquitecto Ventura Rodríguez. Su desaparición se debe a planes de alineaciones de manzanas del siglo XIX, y se verificó en 1870 alegando que el templo amenazaba ruinas para despejar en cierto modo el gran clamor popular ante la destrucción de su más querida iglesia. Lo único que nos queda de ella es una de sus campanas, actualmente en la catedral de la Almudena y algunos restos surgidos en las urbanizaciones de la zona en 1998: un arranque de ábside curvo del siglo XII, el nuevo ábside del siglo XVII -rectangular y que sostenía el camarín de la virgen- y parte de los refuerzos y reformas del año 1777, sobre todo de la zona absidial y de la fachada.

El desfile irá llegando por la calle Mayor hasta acabar frente al pórtico de Santa María la Mayor donde espera el arzobispo de Toledo, ya que la villa de Madrid dependía de esta diócesis. Este va vestido de pontifical y con una gran cruz en las manos que normalmente pertenece al tesoro de la monarquía y que contiene una reliquia del Lignum Crucis ${ }^{16}$ alumbrada por cuatro pajes con hachas. ${ }^{17} \mathrm{El}$ prelado es acompañado por dos diáconos y otros capellanes de honor, vestidos con capas, además de un ayuda de oratorio, que portaría el guión de la capilla. Toda la parte del pórtico que han de pisar los clérigos y el soberano estará lujosamente alfombrada. Una vez se apea el rey, lo hacen también los embajadores, Grandes de España, mayordomos y gentileshombres de cámara, que se acercarán junto a él a las gradas del templo y más tarde entrarán a los oficios, quedando el resto de la comitiva fuera. Allí se adelanta el arzobispo toledano, cuando el mayordomo mayor sirve la almohada sobre la que el monarca se arrodillará para adorar la cruz que porta el prelado. Una vez realizado este acto entraban en la iglesia, donde el rey tenía el sitial preparado, y el prelado se dirigía al altar mayor mientras el coro cantaba un Te Deum en acción de gracias, cosa que se convertirá en una tradición de

16. Las reliquias de lignum crucis atienden a una vieja leyenda medieval según la cual la cruz en la que Cristo fue sacrificado está rota en pequeños trozos que se repartirán por toda la Cristiandad. La monarquía hispànica tenía una, pero también la mayor parte de catedrales importantes de toda Europa e incluso de América.

17. Las hachas o hachones son grandes velas de cera que conatan de cuatro pábilos (hilos que funcionan como mecha para ir quemando la cera una vez éstos se encienden). 
las más arraigadas en las entradas triunfales hispánicas. A continuación, el arzobispo dirá los versos y oraciones dispuestas para ello en el ceremonial romano, para más tarde dar su bendición y acabar con ello los oficios religiosos de la entrada. Al término de la misa, el soberano volverá a las gradas del templo y subirá al caballo con el mismo ceremonial que el observado en el punto de arranque. El coro lo acompañará cantando hasta los últimos términos de los muros de la iglesia de Santa María la Mayor.

Acabado este ceremonial normalmente se habrá hecho de noche, por lo cual se adelantarán los pajes hasta delante del palio para llevar multitud de hachas que iluminen al monarca y al desfile entero, aumentando así más aún el efectismo de estas entradas, como marcaba el gusto barroco de la época. Volverán por la calle Mayor y será ahora cuando se realice una parada en la plaza Mayor, profusamente decorada y con un enorme espectáculo de luminarias y velas que debía ser realmente grandioso. Tras cruzarla volvería a la calle Mayor y en la Puerta del Sol esta vez se endereza por la carrera de San Jerónimo, para bajar otra vez hasta el paseo del Prado y llegar el desfile a su final en el Palacio del Buen Retiro. Una vez allí, el rey volvería a apearse en la gradilla del zaguán y subiría por la escalera principal, entrando por la sala, saleta y antecámara hasta sus aposentos, ya aclamado como monarca por todo el pueblo.

En cuanto a la descripción de los adornos de la carrera para estas entradas triunfales, en primer lugar hay que hablar de la arquitectura efímera, de gran importancia en estas celebraciones, y que constaba básicamente de arcos triunfales, construcciones columnarias, obeliscos, altares efímeros y arcadas. Aparte encontramos las decoraciones en fachadas y puertas de la carrera (colgaduras de telas de oro y seda, bordados, espejos, retratos del monarca), esculturas exentas y en algunos casos carros triunfales, único elemento dinámico de estos espectáculos, a parte de los muy celebrados castillos de fuego y espectáculos pirotécnicos. Sobre ellos, se desplegaría todo el programa iconográfico de la entrada triunfal, que además de retratos de la familia real y sobre todo del monarca seguiría una serie de temáticas que son muy variadas, alegóricas (con representaciones de las virtudes del nuevo monarca y su buen gobierno, como la Justicia o la Paz), mitológicas - siendo los personajes más usados serán Hércules, Atlas o Neptuno-, históricas protagonizadas por la dinastía reinante o por algunos emperadores romanos, temas religiosos, Exempla (basados en los «espejos de príncipes», o sobre como se ha de actuar para el buen gobierno), temas emblemáticos constantes como el Sol, el León o el Águila, ${ }^{18} \mathrm{y}$ algunos temas fantásticos.

18. Para el estudio de la iconografía de la monarquía hispánica a través de los siglos son muy interesantes diversas obras de Víctor MíNGUEz, Los reyes distantes. Imágenes del poder en el México virreinal. Universitat Jaume I - Diputación de Castellón, Castellón, 1995, «Leo fortis, rex fortis. El león y la monarquía hispànica», en Mínguez, V. Y Chust, M., El Imperio Sublevado, Ed. Biblioteca de Historia de América, CSIC, Madrid, 2004 o Los reyes solares: iconografía astral de la monarquía hispánica, Universitat Jaume I, Castellón, 2001, para los casos solares y del león, y del mismo junto a Inmaculada RODRíGUEZ, «Los imperios del águila», en Ivana Frasquet, Bastillas, cetros y blasones: la independencia en Iberoamérica, Madrid, Fundación Mapfre- Tavera, 2006, en lo referente a las águilas. 


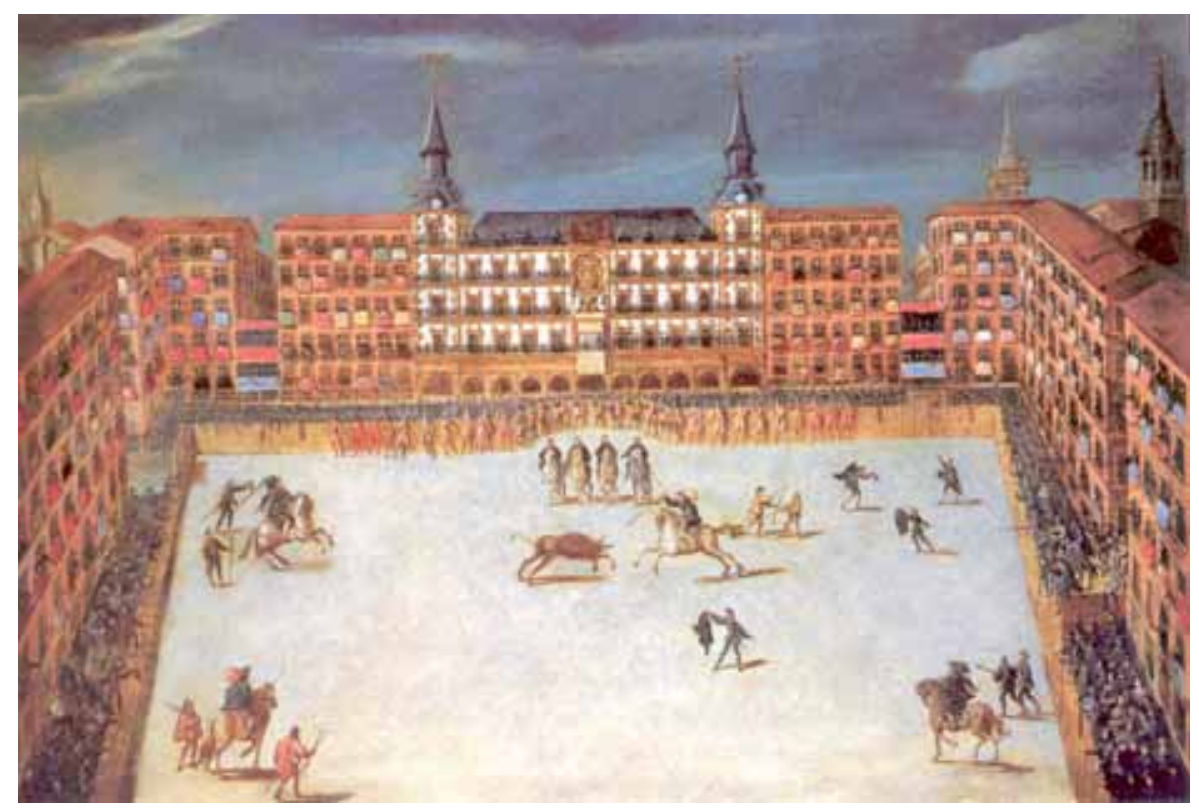

Fig. 10. Anónimo, Vista de la Plaza Mayor de Madrid con corrida de toros (Siglo XVII). Óleo sobre lienzo. Colección Abelló, Madrid

Todo ello se completaría con decoraciones florales, arcos vegetales y otras ornamentaciones de cariz más popular. Las festividades y diversiones esenciales en esos días se centrarían en los refrescos, bailes y recepciones para las clases altas del estado, y juegos de cañas o funciones taurinas principalmente en la plaza Mayor, donde el nuevo monarca compartiría por breve tiempo un mismo espacio con el pueblo de la corte. Por tanto, una entrada triunfal cambiaba totalmente la cara de la ciudad y la llenaba de ornato y lujo, de un lujo muy lejano y poco accesible para la inmensa mayoría del pueblo madrileño. Todas las celebraciones, las demostraciones artísticas y el programa iconográfico que ellas mostraban se destinaban al ensalzamiento del monarca y su dinastía, a mostrar a las masas su poder pasado y presente, y las benevolencias de sus futuros gobiernos.

Con este texto, la Etiqueta para la entrada con palio de los Señores Reyes después de su exaltación al trono, de 1651, podemos ver como toda la tradición renacentista de entradas modernas se ha trasladado ya a la corte española, y ha evolucionado como en el resto de Europa hacia la tipología propiamente barroca de exaltación absolutista. Con la llegada de los Borbones en el siglo xviII el ceremonial seguirá estable, funcionando además como una ayuda inmejorable a la hora de legitimar a los reyes de la nueva dinastía frente al pueblo español, se tenía que seguir con las tradiciones a las que estaban acostumbrados los españoles bajo los Austrias. En el siglo xix el ceremonial seguirá con fuerza y ganará elementos de ideología de ensalzamiento del monarca absoluto, pues 
es un momento difícil para estos soberanos desde la invasión francesa y las primeras intentonas de crear un estado liberal en España. Como se ha dicho en varias ocasiones, los cambios más significativos serán los que sufran las arquitecturas efímeras atendiendo a los cambios estilísticos que llevan del Renacimiento al Barroco, de éste al Rococó y más tarde al Neoclasicismo. Aunque las estructuras serán en todo momento clásicas, las decoraciones y ornamentaciones de las mismas cambiarán a lo largo de la evolución de la Historia del Arte. 